đúng $(1,72 \%)$.

- Triệu chứng cơ năng: ngứa $(75,86 \%)$, rát $(29,31 \%)$, đau $(24,14 \%)$.

- Triệu chứng toàn thân: sốt $(70,69 \%)$, mệt mỏi $(55,17 \%)$, viêm đường hô hấp trên (41,38\%), triệu chứng khác $(1,72 \%)$. Không ghi nhận trường hợp bị sưng hạch ngoại vi.

- Vị trí tổn thương: Thường gặp nhất là ở thân mình $(98,28 \%)$, kế đến là đầu mặt cổ $(94,83 \%)$, ít gặp nhất là nhóm niêm mạc $(29,31 \%)$.

- Thương tổn cơ bản: Nhóm mụn nước, mụn nước rốn lõm chiếm tỷ lệ cao nhất $(98,28 \%)$, kế đến là nhóm hồng ban $(91,38 \%)$, thấp nhất là nhóm sẹo $(1,72 \%)$.

\section{Kết quả điêu tri}

- Sau 5 ngày, có $67,24 \%$ bệnh đáp ứng tốt, $32,76 \%$ đáp ứng khá. Sau 10 ngày, có $82,76 \%$ bệnh đáp ứng tốt, 17,24\% đáp ứng khá. Sau 15 ngày, $100 \%$ bệnh nhân đáp ứng tốt.

- Số lần thoa thuốc $\geq 2$ lần cho đáp ứng điều trị tốt hơn thoa $<2$ lần/ngày $(p<0.05)$.

- Ghi nhận 1 trường hợp ngứa da sau 5 ngày điều trị, mất đi sau 10, 15 ngày điều trị.

\section{TÀI LIỆU THAM KHẢO}

1. Ngố Từng Dương (2007), "Nhận xét tình hình, đặc điểm lâm sàng, cận lâm sàng và kết quả điêu trị bệnh thuỷ đậu tại Bệnh viện 103 từ 1/2004 -
6/2007", Nhận xét tình hình, đặc điểm lâm sàng, cận lâm sàng và kết quả điều trị bệnh thuỷ đậu tại Bềnh viên 103 từ 1/2004 - 6/2007, Luận án thạc sĩ y hoc, Hà Nội.

2. Quách Thi Hà Giang (2011), "Nghiên cứu đă̆c điểm lâm sàng, cận lâm sàng và hiệu quả điều trị bệnh thủy đậu bằng uống acyclovir", Luận văn bác sĩ nôii trú bênh viên, Đại hoc Y Hà Nối.

3. Nguyễn Duy Hưng (2017), "Bệnh thủy đậu", Bệnh học Da liễu (Sách đào tạo sau đại học), NXB Y học, Hà Nội, tr. 85-93.

4. Nguyê̂n Văn Kính (2011), "Bệnh thủy đâu", Bài giảng bệnh Truyền nhiếm, Nhà xuất bản Y học, Hà Nội,tr: 273-279.

5. Nguyễn Văn Mùi, Nguyễn Hoàng Tuấn, Trinh Thị Xuân Hòa (2008), "Bệnh thủy đậu", Bệnh Truyền nhiễm và Nhiệt đới, Nhà xuất bản $Y$ học, tr. 166-171.

6. Đoàn Thu Nga (2016), "Nghiên cứu đăcc điểm lâm sàng, các yếu tố liên quan và kết quả điều trị bênh thủy đậu bằng uống Acyclovir tại Bệnh viện Da liễu Cần Thơ năm 2015 - 2016", Luận văn tốt nghiệp bác sĩ đa khoa, Trường Đại học Y Dược Cần Thơ.

7. Đăng Thi Như Nguyệt, Đoàn Thi Diệp Ngọc (2010), "Đăc điểm lâm sàng bênh thủy đâu trẻ em tại bệnh viện Nhi đồng I "Tạp chí Y học Thành phố Hồ Ćhí Minh, tập 14, tr. 367-371.

8. Dương Văn Thanh, Lê Thị Lựu (2015), "Nghiên cứu đặc điểm bệnh thủy đạu ở bệnh nhân điều tri tai khoa truyền nhiễm bênh viên đa khoa trung ươnì Thái Nguyên từ $2013^{\circ}-2015^{\prime \prime}$, Tạp chí Y học Viêt Nam.

\title{
MÁU TƯ DƯớI MÀNG CỨNG CẤP TÍNH: TỈ LỆ, ĐặC ĐIỂM VÀ KẾT QUẢ ĐIỀU TRI
}

\section{TÓM TẮT}

Mục tiêu: Nhận xét tỉ lệ, đặc điểm lâm sàng, tổn thương trên chụp cắt lớp vi tính và kết quả điểu trị máu tư dưới màng cứng cấp tính. Phương pháp: Mồ tả cắt ngang 153 trường hợp máu tụ dưới màng cứng cấp tính điều tri tai khoa Phẫu thuât Thần kinh-Cột sống bệnh viện Đaa khoa tỉnh Thái Bình trong thời gian từ tháng 2 đến tháng 9 năm 2020. Kết quả: 153 bệnh nhân máu tụ dưới màng cứng cấp tính trong tổng số 534 bênh nhân nhâp viện, chiếm tỉ lề 28,6\%. 117 bệnh nhân nam chiếm $(77,8 \%)$, nữ chiếm (22,2\%). Tuổi nhỏ nhất: 8; tuối cao nhất: 96 ; tuổi trung bình: $55,71 \pm 19,99$. Nguyên nhân tai nạn giao thông chiếm (49,7\%); tai nạn sinh hoạt $(43,8 \%)$. Lâm sàng mức độ nhẹ chiếm $87,6 \%$; mức độ trung bình

*Trường Đại họ Y Dược Thái Bình

Chịu trách nhiệm chính: Vũ Minh Hải

Email: vuminhhai777@gmail.com

Ngày nhận bài: 10.5.2021

Ngày phản biên khoa học: 28.6.2021

Ngày duyệt bài: 5.7.2021
$8,5 \%$, chỉ có 3,9\% mức đô nặng. Điều trị nội khoa chiếm $76,5 \%$, phẫu thuật lấy máu tụ $22,9 \%$. Kết quả ra viện ổn định $89,5 \%$, di chứng nhẹ $5,9 \%$, di chứng trung bình 1,3\%. Tử vong và sống thực vật 3,3\%. Kết luân: Chấn thương sọ não máu tụ dưới màng cứng cẩp tính chiếm tỉ lệ $(28,6 \%)$. Thường gặp ở nam giới. Đa số máu tụ dưới màng cứng cấp tính do chấn thương đều được điều trị bảo tồn, với 76,5\% bênh nhân trong nghiền cứu này đạt được kết quả sớm tốt. Chỉ một tỷ lệ nhỏ bệnh nhân được điều trị bảo tồn sẽ xấu đi và cần phải phẫu thuật.

Tư khóa: máu tu dưới màng cứng cấp tính, điều trị bảo tồn máu tụ nội sọ, chấn thương sọ não.

\section{SUMMARY}

\section{ACUTE SUBDURAL HEMATOMA: RATES, CHARACTERISTICS AND TREATMENT OUTCOMES}

Objectives: To evaluate the rates, clinical characteristics, lesions on CT scan and outcomes of treatment of acute subdural hematoma. Methods: A cross-sectional descriptive study was undertaken in 153 cases of acute subdural hematoma treated at the 
Neurological \&Spinal Surgery Department at Thai Binh General Hospital from February to September 2020. Results: 153 patients with acute subdural hematoma out of a total of 534 hospitalized patients, accounting for $28.6 \%$. 117 males (77.8\%), females (22.2\%). Youngest age:8; oldest age: 96 ; medial age: $55.71 \pm$ 19.99. Traffic accidents accounted for (49.7\%); domestic accidents (43.8\%); minor injuries accounted for $87.6 \%$; moderate $8.5 \%$, severe: only $3.9 \%$. Nonoperative treatment accounted for $76.5 \%$, hematoma evacuation surgery $22.9 \%$. The discharge outcomes: stable $89.5 \%$, minor sequelae: $5.9 \%$, moderate sequelae: $1.3 \%$. Mortality and vegetative state $3.3 \%$. Conclusion: Rate of acute subdural hematoma is $(28.6 \%)$. Common in men. The majority of acute subdural hematomas is conservatively treated, with $76.5 \%$ of patients in this study achieving good early outcomes. Only a small proportion of patients treated conservatively would deteriorate and require surgery.

Keywords: acute subdural hematoma, conservative treatment of intracranial hematoma, traumatic brain injury.

\section{I. ĐẶT VẤN ĐỀ}

Chấn thương sọ não máu tụ dưới màng cứng cấp tính là tổn thương hay gặp trong chấn thương sọ não. Tỉ lệ tử vong cao và di chứng còn nặng nề, tổn thương này vẫn còn là thách thức với chuyên khoa hồi sức tích cực và phẫu thuật thần kinh. Do đó, thăm khám bệnh nhân một cách thận trọng, đánh giá chính xác các triệu chứng lâm sàng vẫn là rất cần thiết trong việc chẩn đoán, tiên lượng và điều trị. Chúng tôi nghiên cứu quan sát mô tả cắt ngang 153 bênh nhân máu tụ dưới màng cứng do chấn thương điều trị tại Bệnh viện Đa khoa tỉnh Thái Bình nhằm mục đích nâng cao kết quả điều trị nhóm bệnh này.

\section{II. ĐỐI TƯợNG VÀ PHƯƠNG PHÁP NGHIÊN CỨU}

2.1. Địa bàn nghiên cứu. Bệnh viện Đa khoa tỉnh Thái Bình

2.2. Đối tượng nghiên cứu. 153 bệnh nhân máu tu dưới màng cứng cấp tính điều trị tại khoa Phẫu thuật Thần kinh-Cột sống bệnh viện Đa khoa tỉnh Thái Bình trong khoảng thời gian từ tháng 2 đến tháng 9 năm 2020.

2.3. Phương pháp nghiên cứu. Quan sát mô tả cắt ngang đặc điểm lâm sàng, chẩn đoán hình ảnh và kết quả ra viện

\section{KẾT QUẢ NGHIÊN CứU}

Bảng 3.1 Phân bố theo nhóm tuổi, giới

\begin{tabular}{|c|c|c|c|c|}
\hline \multirow{2}{*}{ Nhóm tuối } & \multicolumn{2}{|c|}{ Nam } & \multicolumn{2}{|c|}{ Nữ } \\
\cline { 2 - 5 } & $\mathbf{n}$ & $\mathbf{\%}$ & $\mathbf{n}$ & $\mathbf{\%}$ \\
\hline$\leq 18$ & 7 & 100 & 0 & 0 \\
\hline $19-29$ & 14 & 93,3 & 1 & 6,7 \\
\hline $30-39$ & 11 & 84,6 & 2 & 15,4 \\
\hline
\end{tabular}

\begin{tabular}{|c|c|c|c|c|}
\hline $40-49$ & 12 & 80,0 & 3 & 20,0 \\
\hline $50-59$ & 22 & 81,5 & 5 & 18,5 \\
\hline $60-69$ & 28 & 77,8 & 8 & 22,2 \\
\hline $70-79$ & 17 & 77,3 & 5 & 22,7 \\
\hline$\geq 80$ & 8 & 44,4 & 10 & 55,6 \\
\hline Tống & $\mathbf{1 1 9}$ & $\mathbf{7 7 , 8}$ & $\mathbf{3 4}$ & $\mathbf{2 2 , 2}$ \\
\hline
\end{tabular}

Nhận xét: Tuối nhỏ nhất: 8; Tuối cao nhất:

96; Tuổi trung bình: 55,71 $\pm 19,99$

Nam chiếm $77,8 \%$, nữ chiếm $22,2 \%$

Bảng 3.2 Nguyên nhân chấn thương

\begin{tabular}{|c|c|c|c|}
\hline $\begin{array}{c}\text { Nguyên nhân chấn } \\
\text { thương }\end{array}$ & $\mathbf{n}$ & $\begin{array}{c}\text { Tỷ lệ } \\
\mathbf{\%}\end{array}$ & $\begin{array}{c}\text { Tống } \\
\mathbf{\%}\end{array}$ \\
\hline Tai nạn giao thông & 76 & 49,7 & \multirow{2}{*}{98,7} \\
\hline Tai nạn lao động & 8 & 5,2 & \multirow{2}{*}{9} \\
\hline Tai nạn sinh hoạt & 67 & 43,8 & \\
\hline Bạo lực & 2 & 1,3 & 1,3 \\
\hline Tống & $\mathbf{1 5 3}$ & $\mathbf{1 0 0}$ & $\mathbf{1 0 0}$ \\
\hline
\end{tabular}

Nhận xét: Tai nạn giao thông chiếm 49,7\%;

tai nan sinh hoat $43,8 \%$, tai nan lao động $(5,2 \%)$.

Bảng 3.3 Các triệu chứng lâm sàng

\begin{tabular}{|c|c|c|}
\hline Triệu chứng lâm sàng & n & Tỷ lệ \% \\
\hline Hôn mề & 9 & 5,9 \\
\hline Đau đâu & 134 & 87,6 \\
\hline Nôn & 32 & 20,9 \\
\hline Chảy máu mũi & 6 & 3,9 \\
\hline Chảy máu tai & 12 & 7,8 \\
\hline Bầm tím quanh mắt & 13 & 8,5 \\
\hline Tụ máu, sưng nề dưới da đầu & 42 & 27,5 \\
\hline Vêt thương vùng đầu & 45 & 29,4 \\
\hline Liệt 11/2 người & 15 & 9,8 \\
\hline Liệt dây VII & 2 & 1,3 \\
\hline Giãn đồng tử 1 bên & 1 & 0,7 \\
\hline Khoảng tînh & 5 & 3,3 \\
\hline
\end{tabular}

Nhân xét: Triêu chứng đau đầu $87,6 \%$; nôn chiếm $20,9 \%$, tụ máu, sưng nề da đầu $27,5 \%$, vết thương vùng đầu $29,4 \%$, liệt nửa người chiếm $9,8 \%$.

Bảng 3.4 Mức độ nặng theo tri giác

\begin{tabular}{|c|c|c|}
\hline GCS & $\mathbf{n}$ & Tỷ lệ $\%$ \\
\hline $13-15$ điếm & 134 & 87,6 \\
\hline $9-12$ điếm & 13 & 8,5 \\
\hline $3-8$ điếm & 6 & 3,9 \\
\hline Tống & $\mathbf{1 5 3}$ & $\mathbf{1 0 0}$ \\
\hline
\end{tabular}

Nhận xét: Tình trạng lâm sàng mức độ nhẹ chiếm $87,6 \%$; mức độ trung bình $8,5 \%$, chỉ có 3,9\% mức độ nặng.

Bảng 3.5 Tổn thương phôi hợp trên phim chup CLVT

\begin{tabular}{|c|c|c|}
\hline Tốn thương & $\mathbf{n}$ & Tỷ lệ $\%$ \\
\hline Vỡ xương sọ & 23 & 15,0 \\
\hline Phù não nặng & 2 & 1,3 \\
\hline Máu tụ ngoài màng cứng & 13 & 8,5 \\
\hline Máu tứ trong não & 6 & 3,9 \\
\hline Chảy màu màng mềm & 44 & 28,8 \\
\hline
\end{tabular}


Nhận xét: Võ̃ xương sọ chiếm 15,0\%, chảy máu màng mềm $28,8 \%$, máu tụ ngoài màng cứng $8,5 \%$.

Bảng 3.6 Tổn thương phôi hợp

\begin{tabular}{|c|c|c|}
\hline Tốn thương phối hợp & $\mathbf{n}$ & Tỷ lệ \% \\
\hline Vết thương rách da & 42 & 27,5 \\
\hline Vết thương bàn tay & 5 & 3,3 \\
\hline Chẫn thương hàm mặt & 20 & 13,1 \\
\hline Chấn thương cột sống cố & 2 & 1,3 \\
\hline $\begin{array}{c}\text { Chấn thương cồt sống ngực } \\
\text { thắt lứng }\end{array}$ & 2 & 1,3 \\
\hline Chẫn thương ngực & 8 & 5,2 \\
\hline Gãy xương chi & 18 & 11,8 \\
\hline
\end{tabular}

Nhân xét: Vết thương rách da chiếm 27,5\%, chấn thương hàm mặt $13,1 \%$, gãy xương chi $(11,8 \%)$, chấn thương ngực 5,2\%.

\section{Bảng 3.7 Thái đô xứ trí}

\begin{tabular}{|c|c|c|}
\hline Thái độ xử trí & $\mathbf{n}$ & Tỷ lệ \% \\
\hline Hồi sức tích cực & 1 & 0,6 \\
\hline Nội khoa & 117 & 76,5 \\
\hline Phẩu thuật lấy máu tụ & 32 & 20,9 \\
\hline $\begin{array}{c}\text { Phẩu thuật lấy máu tụ }+ \\
\text { giải tỏa não }\end{array}$ & 3 & 2,0 \\
\hline Tô̂ng số & $\mathbf{1 5 3}$ & $\mathbf{1 0 0}$ \\
\hline
\end{tabular}

Nhận xét: Đa số điều trị nội khoa chiếm $76,5 \%$, phẫu thuật lấy máu tụ 22,9\%.

Bảng 3.8 Tình trạng ra viện

\begin{tabular}{|c|c|c|}
\hline Kểt quả điều trị & $\mathbf{n}$ & Tỷ lệ $\%$ \\
\hline Tốt (GCS 14-15đ) & 137 & 89,5 \\
\hline Khá (GCS 12-13đ) & 9 & 5,9 \\
\hline Trung bình (GCS 9-11đ) & 2 & 1,3 \\
\hline Kém (GCS 3-8đ) & 4 & 2,6 \\
\hline Tứ vong & 1 & 0,7 \\
\hline Tống & $\mathbf{1 5 3}$ & $\mathbf{1 0 0}$ \\
\hline
\end{tabular}

Nhận xét: Kết quả ra viện ốn định $89,5 \%$, di chứng nhe 5,9\%, di chứng trung bình 1,3\%. Tử vong và sống thực vật 3,3\%.

\section{BÀN LUẬN}

4.1 Tỉ lệ máu tụ dưới màng cứng cấp tính. 153 bệnh nhân máu tụ dưới màng cứng cấp tính trong tổng số 534 bệnh nhân nhập viện, chiếm tỉ lệ $(28,6 \%)$ trong thời gian từ tháng 2 đến tháng 9 năm 2020 điều trị tại khoa Phẫu thuật Thần kinh-Cột sống bệnh viện Đa khoa tỉnh Thái Bình. Tî lệ máu tụ dưới màng cứng của chúng tôi cao hớn báo cáo của Massaro $F$, Lanotte $M$ và cộng sự (1996), trong 10 năm từ 1982 đến 1992 có 127 bệnh nhân máu tụ dưới màng cứng cấp tính trên tổng sô 1688 bệnh nhân chấn thương sọ não chiếm tỉ lệ $(7,5 \%)$ [2]. Theo Bajsarowicz, P., Prakash (2015) cho biết máu tụ dưới màng cứng cấp tính do chấn thương chiếm tỉ lệ 12\%-29\% tổng số bệnh nhân chấn thương sọ nã̃o nặng nhập viện [3].
4.2 Tuổi, giới. Trong nghiên cứu này tuổi nhỏ nhất là 8 tuổi, tuổi cao nhất là 96; Tuổi trung bình: $55,71 \pm 19,99$. Theo Nguyễn Thanh Nam (2020), tại bệnh viện Đa khoa tỉnh Vĩnh Phúc phẫu thuật 46 bệnh nhân máu tụ dưới màng cứng cấp tính gặp bệnh nhân cao tuổi nhất là 83 tuổi và bệnh nhân nhỏ tuổi nhất là 5 tuổi. Tuổi trung bình của nhóm nghiên cứu là $41 \pm 19,3$ [1]. Theo Massaro $F$, Lanotte $M$ và cộng sự (1996) độ tuổi dao động từ 3 đến 93 tuổi. Độ tuổi trung bình là 47, có 94 nam và 33 nữ.

Giới: Bệnh nhân nam chiếm $77,8 \%$, nữ chiếm $22,2 \%$, tỉ lệ này tương đương với tác giả Nguyễn Thanh Nam (2020), nam chiếm 78\%, nữ 22\% [1].

4.3 Nguyên nhân tai nạn. Chúng tôi ghi nhận nguyên nhân tai nạn giao thông chiếm 49,7\%; tai nạn sinh hoạt $43,8 \%$, tai nạn lao động (5,2\%). Kết quả của chúng tôi thấy nguyên nhân do tai nạn giao thông thấp hơn báo cáo của Nguyễn Thanh Nam, nguyên nhân chấn thương do tai nạn giao thông chiếm tỷ lệ cao nhất $(68 \%)$, tiếp theo là tai nạn lao động ngã cao (17\%), tai nạn sinh hoạt (13\%).

4.4 Lâm sàng và chẩn đoán hình ảnh. Tình trạng lâm sàng khi vào viện đánh giá theo GCS mức độ nhẹ (GCS 13-15) chiếm 87,6\%; mức độ (GCS 9-12) trung bình 8,5\%, chỉ có 3,9\% mức độ nặng (GCS 3-8). Vết thương rách da chiếm $27,5 \%$, chấn thương hàm mặt $(13,1 \%)$, gãy xương chi $(11,8 \%)$, chấn thương ngực 5,2\%.

Chụp cắt lớp vi tính thây tổn thương máu tụ dưới màng cứng kèm võ xương so chiếm $15,0 \%$, chảy máu màng mềm $28,8 \%$, máu tụ ngoài màng cứng $8,5 \%$.

4.5 Kết quả điêu trị khi ra viện. Đa số nhóm bệnh nhân của chúng tôi mức độ lâm sàng nhe nên điều trị nội khoa chiếm đa số $(76,5 \%)$, phẩu thuật lấy máu tụ 35/153 bệnh nhân chiếm $(22,9 \%)$. Chúng tôi chỉ định mổ khi lâm sàng tri giác giảm 2 điểm GCS và chụp cắt lớp kiểm tra thấy máu tụ dày trên $10 \mathrm{~mm}$, đường giữa đè đầy trên $5 \mathrm{~mm}$. Có 12 bệnh nhân lúc đầu vào viện tri giác tốt, sau theo dõi 5 ngày có tri giác xẩu đi, chụp kiểm tra thấy phù não tăng lên, đè đẩy đường giữa trên $10 \mathrm{~mm}$ nên được chỉ định phẫu thuật, kết quả bệnh nhân hồi phục tốt. Kết quả chung khi ra viện viện ổn định $89,5 \%$, di chứng nhe $5,9 \%$, di chứng trung bình $1,3 \%$. Tử vong và sống thực vật $3,3 \%$. Kết quả của chúng tôi tương tự tác giả Bajsarowicz, P., Prakash (2015) và cộng sự: hầu hết các máu tụ dưới màng cứng cấp tính do chấn thương đều được quản lý bảo tồn (77\%) bệnh nhân đạt được kết quả sớm tốt [3]. 


\section{KẾT LUẬN}

Chấn thương sọ não máu tụ dưới màng cứng cấp tính chiếm tỉ lệ (28,6\%). Thường gặp ở nam giới. Đa số máu tụ dưới màng cứng cấp tính do chấn thương đều được điêuu trị bảo tôn, với 76,5\% bệnh nhân trong nghiên cứu này đạt được kết quả sớm tốt. Chỉ một tỷ lệ nhỏ bệnh nhấn được điều trị bảo tôn sẽ xấu đi và cân phải phẫu thuật.

\section{TÀI LIÊU THAM KHẢO}

1. Nguyễ̃n Thanh Nam (2020), "Kết quả điều trị phâu thuật máu tụ dưới màng cứng cấp tính tạ Bệnh viện Đa khoa tỉnh Vĩnh Phúc", luận văn tổt nghiệp bác sĩ chuyên khoa 2, Đai học Y'Hà Nội, 2020.

2. Massaro F, Lanotte M (1996), One hundred and twenty-seven cases of acute subdural haematoma operated on. Correlation between CT scan findings and outcome. Acta Neurochir (Wien) 138:185-191, 1996.

3. Bajsarowicz, P., Prakash, I.,(2015). Nonsurgical acute traumatic subdural hematoma: what is the risk? Journal of Neurosurgery, 123(5), 1176-1183.

\title{
KẾT QUẢ PHẪU THUÂTT ĐIỀU TRI HộI CHỨNG ỐNG CỔ TAY MỨC Độ NẶNG VÀ̀ RẤT NẶNG
}

\author{
Dương Đình Toàn' ${ }^{1}$, Nguyễn Đình Hưng ${ }^{2}$, Hoàng Văn Ba ${ }^{2}$
}

\section{TÓM TẮT}

Chúng tôi tiến hành phẫu thuật điều trị cho 38 bệnh nhân với 42 bàn tay được chẩn đoán là hội chứng ống cổ tay (OCT) mức độ nặng và rất nặng. Thời gian theo dõi sau mổ 24 tháng. Mục tiêu: Đánh giá kết quả phẫu thuật điều trị hội chứng OCT mức độ nặng và rất nặng. Phương pháp nghiên cứu: Thăm khám, lựa chọn bệnh nhân được chẩn đoán hội chứng OCT mức độ nặng và rất nặng, tiến hành phẫu thuật cắt dây chẳng ngang OCT giải phóng chèn ép thần kinh giữa; theo dõi, đánh giá kết quả sau mổ bằng thang điểm Boston và các test lâm sàng. Kết quả: Sau mổ 24 tháng, điểm Boston từ 4,55 điểm xuống còn 2 điểm, tỷ lệ dương tính với với các nghiệm pháp Tinel, Phalen, Durkan không còn. Triệu chứng tê bì gảm, tuy nhiên teo cơ mô cái hồi phục chậm. Kết luâan: Phẫu thuật cắt dây chằng ngang giải phóng thẩn kinh giữa trong hội chứng OCT mức độ năng và rất nặng giúp cải thiện đáng kể chức năng khớp cổ tay.

\section{SUMMARY}

\section{RESULT OF SURGERY TREATMENT OF SEVERE AND VERY SEVERE CARPAL TUNNEL SYNDROME (CTS)}

We performed surgical treatment for 38 patients with 42 hands diagnosed with severe and very severe carpal tunnel syndrome (CTS). Postoperative follow-up time 24 months. Objective: Evaluated the surgical outcomes for severe and very severe OCT syndrome. Methods: Examination and selection of patients diagnosed with severe and very severe CTS, surgical removal of the transverse ligament to release compression of the median nerve; Monitor and

${ }^{1}$ Đại Học Y Hà Nọi,

${ }^{2}$ BV Đa khoa Xanh Pôn

Chịu trách nhiệm chính: Dương Đình Toàn

Email: duongdinhtoan@hmu.edu.vn

Ngày nhận bài: 7.5.2021

Ngày phản biện khoa học: 25.6.2021

Ngày duyệt bài: 2.7.2021 evaluate the results after surgery using the Boston questionaire and clinical tests. Results: After 24 months of surgery, Boston score from 4.55: points to 2 points, the positive rate with Tinel, Phalen, Durkan tests no longer exists. Symptoms of numbness and tingling are reduced, but muscle atrophy recovers slowly. Conclusion: transverse ligament to release compression of the median nerve in severe and very severe CTS could improves significantly wrist joint function.

Keywords: Carpal tunne syndrome; Median nerve

\section{I. Đă̆T VẤN ĐỀ}

Hội chứng ống cổ tay $(\mathrm{OCT})$ là tình trạng chèn ép thần kinh giữa khi nó đi qua ống cổ tay, đây là hội chứng hay gặp nhất trong các bệnh lý chèn ép dây thần kinh ngoại biên. Hậu quả của việc chèn ép dây thần kinh giữa gây ra triệu chứng đau, tê, giảm hoặc mất cảm giác vùng da bàn tay thuộc chi phối của thần kinh, nặng hơn có thể gây teo cớ, giảm chức năng và vận động bàn tay. Điều trị HC OCT bao gồm điều trị nội khoa và ngoại khoa. Trong đó điều trị nội khoa được chỉ định với những bệnh nhân đên trong giai đoạn sớm của bệnh, với việc sử dụng nẹp cổ tay, uống hoặc tiêm corticoid tại ống cố tay làm giảm triệu chứng nhanh, tuy nhiên triệu chứng tái phát sớm ${ }^{1}$. Điều trị phẫu thuật cắt dây chằng ngang cổ tay là phương pháp điều trị triệt để nhất, chỉ định khi bệnh nhân đến trong giai đoạn nặng, hoặc đã điều trị nội khoa thất bại. Tại Việt Nam, tình trạng người bệnh đến khám khi bẹnh ở giai muộn khá phổ biến, việc điều trị trở nên khó khăn hơn, hiệu quả điều trị không như mong muốn. Trên cớ sở số liệu có được, chúng tôi thực hiên đề tài này nhằm mục tiêu đánh giá kết quả phẫu thuật điêu trị hội chứng OCT mức độ nặng và rất nặng. 